\title{
Critical Review of Norovirus Surrogates in Food Safety Research: Rationale for Considering Volunteer Studies
}

\author{
Gary P. Richards
}

Received: 24 October 2011/Accepted: 17 November 2011/Published online: 9 December 2011

(C) The Author (outside the USA) 2011. This article is published with open access at Springerlink.com

\begin{abstract}
The inability to propagate human norovirus (NoV) or to clearly differentiate infectious from noninfectious virus particles has led to the use of surrogate viruses, like feline calicivirus (FCV) and murine norovirus1 (MNV), which are propagatable in cell culture. The use of surrogates is predicated on the assumption that they generally mimic the viruses they represent; however, studies are proving this concept invalid. In direct comparisons between FCV and MNV, their susceptibility to temperatures, environmental and food processing conditions, and disinfectants are dramatically different. Differences have also been noted between the inactivation of $\mathrm{NoV}$ and its surrogates, thus questioning the validity of surrogates. Considerable research funding is provided globally each year to conduct surrogate studies on NoVs; however, there is little demonstrated benefit derived from these studies in regard to the development of virus inactivation techniques or food processing strategies. Human challenge studies are needed to determine which processing techniques are effective in reducing NoVs in foods. A major obstacle to clinical trials on NoVs is the perception that such trials are too costly and risky, but in reality, there is far more cost and risk in allowing millions of
\end{abstract}

Disclaimer: The use of trade names or commercial products in this publication is solely for the purpose of providing specific information and does not imply recommendation or endorsement by the United States Department of Agriculture (USDA). The USDA is an equal opportunity provider and employer. The opinions expressed in this article are those of the author and do not constitute endorsement by the USDA or the Federal Government.

\section{G. P. Richards $(\bowtie)$}

U.S. Department of Agriculture, Agricultural Research Service, Delaware State University, James W.W. Baker Center, Dover, DE 19901, USA

e-mail: gary.richards@ars.usda.gov unsuspecting consumers to contract NoV illness each year, when practical interventions are only a few volunteer studies away. A number of clinical trials have been conducted, providing important insights into NoV inactivation. A shift in research priorities from surrogate research to volunteer studies is essential if we are to identify realistic, practical, and scientifically valid processing approaches to improve food safety.

Keywords Norovirus inactivation - Surrogate · Feline calicivirus - Murine norovirus - Clinical trials . Food safety $\cdot$ Volunteer study

\section{Introduction}

Human noroviruses (NoVs) are a primary cause of viral gastroenteritis throughout the world (Siebenga et al. 2009), and the principle cause of foodborne illness in Europe (Kroneman et al. 2008; Phillips et al. 2010) and the United States (Mead et al. 1999; Scallan et al. 2011). The number of estimated cases in the United States was recently revised to 5.5 million annually (Scallan et al. 2011), while England has an estimated 2 million cases per year (Phillips et al. 2010). As enteric viruses, the NoVs are spread via the feces or vomitus of infected individuals. Norovirus illness is contracted through contaminated food and water and direct person-to-person transmission. Contamination often arises during the handling and preparation of foods, although there are many instances where foods, particularly shellfish, are contaminated within their environment. Products requiring extensive handling are also prone to contamination. In spite of interventions to eliminate product contamination, like thorough cooking, some products, such as salads and molluscan shellfish are typically eaten raw or 
only lightly cooked and such products represent the greatest risk to the consumer (Richards 2001; Richards et al. 2010).

The development of commercial processing strategies for foods has been largely based on reductions in bacterial pathogens, and only to a lesser extent on the inactivation of enteric viruses. For some of the enteric viruses, like poliovirus and related Picornaviridae, astroviruses, parvoviruses, rotaviruses, and adenoviruses 40 and 41 , the levels of infectious virus particles can be determined using cell or tissue culture, since these viruses are propagatable. Unfortunately, NoV cannot be routinely propagated in cell culture or animal models. Human exposure and resulting illness are currently the only means to distinguish infectious from inactivated NoVs. Scientists and regulators have relied on virus detection in foods based on the physical presence of viral RNA, as determined by reverse transcription-PCR, which presently cannot distinguish between infectious and inactivated viruses (Richards 1999), although methods are being developed toward that goal ( $\mathrm{Li}$ et al. 2011; Nuanualsuwan and Cliver 2002; Parshionikar et al. 2010). The lack of a suitable assay for infectious NoV and other unculturable viruses, like most wild-type strains of hepatitis A virus (HAV), has led the research community to focus on viral surrogates. Surrogates are viruses related to the pathogens they have been chosen to represent. The selection of a surrogate, at least in regard to NoVs, has been based on the ability of the surrogate to be propagated in culture, and its genetic, physical, or chemical relatedness to the pathogen. Over the years, different surrogates have been selected for use in determining the uptake, persistence, distribution, and inactivation of viruses in foods, water, and environmental samples as well as in chemical disinfection studies on surfaces. Studies with surrogates have been used with the intent to develop a better understanding about the pathogens they represent as well as applied applications for pathogen elimination.

A respiratory virus known as feline calicivirus (FCV) in the genus Vesivirus was first used as a NoV surrogate in the late 1990s (Doultree et al. 1999; Slomka and Appleton 1998). It has been commonly employed in studies involving chemical disinfectants (Cannon et al. 2006; D’Souza and Su 2010; Doultree et al. 1999; Gehrke et al. 2004; Hudson et al. 2007; Jimemez and Chiang 2006; Kampf et al. 2005; Lages et al. 2008; Malik et al. 2006; Malik and Goyal 2006; Mori et al. 2007; Morino et al. 2009; Poschetto et al. 2007; Sattar et al. 2011; Steinmann 2004; Urakami et al. 2007; Whitehead and McCue 2010); and processing interventions, like heating (Buckow et al. 2008; Butot et al. 2009; Cannon et al. 2006), freezing or freezedrying (Butot et al. 2008, 2009), irradiation (de Roda Husman et al. 2004; Fino and Kniel 2008; Nuanualsuwan et al. 2002), marinating/acidification (Cannon et al. 2006;
Hewitt and Greening 2004), and high pressure processing (Chen et al. 2005; Kingsley et al. 2002). A decade after FCV first came on the scene, Wobus et al. (2006) identified murine norovirus-1 (MNV) as a closer genetic relative of NoV. Now, MNV has become the more commonly used surrogate for chemical disinfection studies (Belliot et al. 2008; Cannon et al. 2006; D'Souza and Su 2010; Lee et al. 2008; Lim et al. 2010; Magulski et al. 2009; Park et al. 2010; Sattar et al. 2011); and studies on processing interventions like heating (Baert et al. 2008a; Cannon et al. 2006; Hewitt et al. 2009; Sow et al. 2011; Tanner 2009), freezing (Baert et al. 2008b), UV irradiation (Jean et al. 2011; Park et al. 2011), gamma irradiation (Feng et al. 2011), electron beam (Sanglay et al. 2011), and high pressure processing (Kingsley et al. 2007; Lou et al. 2011; Tang et al. 2010). Poliovirus and bacteriophage MS2 have also been used as potential surrogates for NoV (Bae and Schwab 2008; D’Souza and Su 2010; Dawson et al. 2005; Shin and Sobsey 2003). Another potential surrogate is the recently discovered rhesus monkey calicivirus, known as Tulane virus, which can replicate in cell culture, but as indicated by Tan and Jiang (2010), may not serve as a good model for human NoV because it is not in the norovirus genus and has not been shown to cause gastroenteritis like the human NoVs. Unfortunately, there are fundamental differences in the inactivation rates of many closely related viruses-differences which may limit their role as surrogates.

\section{Limitations of Viral Surrogates}

Surrogate viruses are generally expected to mimic the viruses they represent, although studies are proving this concept invalid. In direct comparisons between FCV and $\mathrm{MNV}$, their susceptibility to temperatures, $\mathrm{pH}$, and environmental conditions has been shown to be dramatically different (Cannon et al. 2006). In these studies, MNV was significantly more resistant to both acidic and alkaline $\mathrm{pHs}$ than FCV; MNV was more resistant than FCV to chloroform, Freon, and Vertrel; FCV was more stable than MNV at $56^{\circ} \mathrm{C}(P<0.05)$, but differences were not significant at 63 and $72^{\circ} \mathrm{C}$; and $\mathrm{MNV}$ was more stable in solution at room temperature (Cannon et al. 2006). Gibson and Schwab (2011) reported that FCV was significantly less stable than $\mathrm{MNV}$ at $50^{\circ} \mathrm{C}$, but not significantly different at $60^{\circ} \mathrm{C}$. In these same studies, HAV was significantly more resistant than FCV and MNV to heat treatment at 50 and $60^{\circ} \mathrm{C}$ (Gibson and Schwab 2011). Bae and Schwab (2008) evaluated the persistence of FCV, MNV, MS2 and poliovirus in surface water and groundwater and found that FCV was significantly less stable than MNV, MS2, and poliovirus. Sattar et al. (2011) compared the effects of 
ethanol-based hand rubs to eliminate FCV and MNV. They showed that over a short contact time (20 s) that FCV was 100 times more resistant to inactivation than MNV. In another study on hand sanitizers, FCV was more sensitive to some low $\mathrm{pH}$ sanitizers than MNV; however, MNV was more readily inactivated by alcohols, thus the recommendation was made to include both surrogates when testing hand sanitizers (Park et al. 2010). A study on the inactivation of FCV and MNV by UV irradiation (254 nm) showed FCV to be more sensitive than MNV (Park et al. 2011). D'Souza and Su (2010) evaluated the effects of chemical treatments to inactivate FCV, MNV, and MS2 and reported that a $2 \%$ trisodium phosphate treatment for 1 min decreased FCV and MS2 by over $6 \operatorname{logs}$, but MNV by only $1 \log$. They also showed that $2 \%$ glutaraldehyde reduced FCV and MNV titers by 6 logs, but MS2 by $<3$ logs. Seventy percent ethanol was reported to cause no reduction in titers for any of the viruses (D'Souza and Su 2010). Ueki et al. (2007) compared the persistence of NoV and FCV in the digestive tissues of the oyster after depuration for 10 days and concluded that FCV was rapidly depleted, whereas NoV persisted. We now know that NoV binds to histo-blood group antigens (HBGAs) present on gastrointestinal cells of oysters, clams, and mussels (Le Guyader et al. 2006; Tian et al. 2006, 2007), which may account for differences in virus uptake by shellfish. Tulane virus also binds to HBGAs (Farkas et al. 2010), while MNV and FCV bind to sialic acid on the host cell surface (Stuart and Brown 2007; Taube et al. 2009). These results should lead one to conclude that not all virus surrogates are equal; some surrogates are more similar while others are quite different from the pathogens they represent.

A major limitation in these studies is a lack of correlation in the inactivation rates of the surrogates and of the pathogen. Koopmans and Duzier (2004) suggested the use of the most resistant enteric virus in developing food safety guidelines. This may over regulate the industry if $\mathrm{NoV}$ is substantially more susceptible than the surrogate. On the other hand, even the most resilient surrogate may not be as resistant as the pathogen, and may lead to a false sense of security relative to the safety of food or water. Unfortunately, there is often no information available to directly correlate the pathogen with its ascribed surrogate, leaving regulators unable to promulgate new food regulations based on surrogate studies. In addition, a surrogate may be representative of a pathogen's response to a particular processing scenario (e.g., pasteurization), but may not necessarily represent a pathogen's response under other processing conditions or in other food matrices. Data obtained must be carefully scrutinized and treated as presumptive evidence of how the pathogen may respond to a particular treatment. The use of FCV as a surrogate has diminished as more researchers are utilizing MNV, which is genetically more similar to NoV than FCV. Consequently, past FCV research is being looked on as unreliable, while MNV is rapidly gaining popularity as a more suitable surrogate, in spite of the fact that FCV seems more resistant to chemical disinfectants than MNV.

The question today is whether $\mathrm{MNV}$ is an adequate surrogate for NoV-one that closely mimics the virus it represents. Is MNV the answer? Probably not. The reason is that MNV may fail to respond in the same manner as the pathogen it represents. This was demonstrated in a volunteer study involving the inactivation of $\mathrm{NoV}$ in oysters using high pressure processing (Leon et al. 2011). In this study, pressures of up to 600 megaPascals (MPa) for $5 \mathrm{~min}$ at room temperature were required to totally eliminate 4 logs of NoV (Leon et al. 2011). In comparison, only $250 \mathrm{MPa}$ was required to inactivate $7 \mathrm{logs}$ of $\mathrm{FCV}$ in cell culture media under the same conditions, while $4 \operatorname{logs}$ of MNV required $400 \mathrm{MPa}$ for $5 \mathrm{~min}$ at $5^{\circ} \mathrm{C}$ for inactivation (Kingsley et al. 2002, 2007; Leon et al. 2011). One of the problems in comparing such studies is differences in processing conditions or matrix between assays. Here, we see different matrices (cell culture media and oysters) and different processing conditions (room temperature and $5^{\circ} \mathrm{C}$ ); however, no other comparative studies exist for this processing technology.

Another example of the differences in the inactivation of related viruses may be seen for poliovirus and HAV. Poliovirus has been used as a surrogate for HAV because of its similarity in size, shape, and structure to HAV; however, high pressure processing can inactivate HAV at pressures around $400 \mathrm{MPa}$, but poliovirus persists at $600 \mathrm{MPa}$ (Kingsley et al. 2002; Wilkinson et al. 2001). Another study showed that different strains of cell cultureadapted HAV have different sensitivities to heat and high pressure, where heating to $60^{\circ} \mathrm{C}$ for $10 \mathrm{~h}$ and pressures of $420 \mathrm{MPa}$ reduced virus infectivity by anywhere from 3 to 5 logs, depending on the strain (Shimasaki et al. 2009). This represents a 100-fold difference in the inactivation of different strains of HAV and highlights how different strains of the same virus do not accurately portray the inactivation dynamics of all HAV strains. Much like the differences in inactivation noted among HAV strains, different responses to inactivation should be anticipated among the NoV strains. Different strains of FCV also showed widely differing susceptibilities to inactivation by three alcohol mixtures and a chlorine compound (Di Martino et al. 2010) and to $\mathrm{pH}$ and heat (Lee and Gillespie 1973). If strains of the same virus give discordant inactivation results, then one might expect virus surrogates, which are only slightly related to the pathogens, to be poor indicators of the pathogen's inactivation kinetics. NoVs include a variety of genetically similar strains (also called genotypes or clusters) within two genogroups (I and II). The uptake of 
different NoV strains by oysters varied with genogroup I, cluster $1 \mathrm{NoV}$ (Norwalk virus strain) efficiently bioconcentrated, but genogroup II, cluster $4 \mathrm{NoV}$ poorly bioconcentrated (Maalouf et al. 2011). Consequently, the use of a surrogate for viruses that differ widely in their genetic composition and likely in their response to various processing techniques, chemical disinfection, or environmental conditions seems counterproductive. Although the most resistant surrogates may be used to evaluate processing effectiveness, the pathogens could be several orders of magnitude more resistant to treatment than the surrogate. Predictive models have been proposed for NoV and HAV inactivation in shellfish, based on the use of surrogates, either FCV or a cell culture-adapted strain of HAV (Buckow et al. 2008; Grove et al. 2009); however, such models are not likely to accurately portray the inactivation of pathogenic viruses on or within foods. With the likelihood that MNV will not accurately reflect the conditions necessary to inactivate $\mathrm{NoV}$ in foods, one questions the funding of surrogate studies. Will MNV become another FCV, with millions of dollars spent on research but little confidence in the results?

\section{Costs and Benefits}

Considerable research funding is provided globally each year to conduct surrogate studies on NoV; however, there is little benefit derived from these studies in regard to the development of food processing strategies. After years of research with FCV as the surrogate, investigators are considering those results highly presumptuous, particularly in light of MNV which is now generally perceived as a better surrogate. The time, effort, and cost that were devoted to surrogate research with FCV may have been misdirected. At what cost was the FCV research conducted? No one can be sure, but certainly millions of dollars have been spent on what is now considered by most as an ineffectual surrogate. A similar fate will befall MNV when researchers identify still better surrogates for NoV and similar or greater dollar losses can be expected. Uncertainty concerning the reliability of surrogate studies has, to the best of this author's knowledge, prevented results from being implemented in regulatory actions or new food processing procedures. If information were available on how much money was spent on surrogate studies and one were to conduct a cost-benefit analysis on the FCV or MNV studies performed to date, results would be startling, since there has been much money spent, but with little change in the way we process foods or sanitize the workplace. At the time of this writing (September, 2011), a number of papers had already been published during 2011 on the use of $\mathrm{MNV}$ as a NoV surrogate, including the use of varying processing technologies, like electron beam (Sanglay et al. 2011); gamma irradiation (Feng et al. 2011), and high pressure processing (Lou et al. 2011) to inactivate MNV in produce; heat inactivation of MNV in clams (Sow et al. 2011); chemical disinfectants to eliminate MNV on produce and food contact surfaces (Predmore and Li 2011) and hands (Park et al. 2011; Sattar et al. 2011); and pulsed UV light inactivation of MNV on food contact surfaces (Jean et al. 2011). Such studies fail to provide reasonable expectations that the surrogates respond in a similar manner to $\mathrm{NoV}$ or to different genogroups or strains of NoV. In spite of the well intentioned and competent research that has been performed on NoV surrogates, results derived from surrogate studies have not answered the important questions regarding NoV inactivation in foods, water, or on food contact surfaces. We need to ask ourselves if FCV or MNV could ever be used in establishing food processing regulations when they only provide a glimmer of how the pathogen might respond to certain conditions. With all this uncertainty about surrogates, how does one derive definitive answers concerning what methods are needed to inactivate NoVs? The answer is human clinical trials.

\section{Need for Clinical Trials}

Current practices to evaluate surrogate viruses and to employ molecular assays should be limited, particularly for NoV inactivation studies. It is hereby recommended that presumptive information derived from the use of surrogates be subjected to proof-of-principle testing and validated in volunteer studies using NoV. Human challenge studies are essential to determine which processing techniques are effective in reducing $\mathrm{NoV}$ in foods. NoV is considered the primary cause of gastrointestinal illness worldwide. With such high morbidity rates, strategically designed volunteer studies performed under controlled conditions would seem prudent in order to assess the effects of cooking, freezing, irradiation, disinfectants, and other processing technologies on virus inactivation. The cost for challenge studies would be high; however, the results would be definitive. A case in point was the recent volunteer study to assess the effectiveness of high pressure processing to inactivate NoV in oysters, where it was definitively shown that pressure of up to $600 \mathrm{MPa}$ for $5 \mathrm{~min}$ at room temperature would be required to inactivate $4 \operatorname{logs}$ of the genogroup I.1 (Norwalk virus) strain of NoV (Leon et al. 2011). Does this mean that the same processing conditions would be required to inactivate the same level of other NoV strains? No, not at all, but is seems likely that differences between NoV strains would be less than differences between NoVs and their so called surrogates. 
Another example of the benefit of clinical trials involved a study performed in Australia where shellfish containing NoV were "purified" by depuration (Grohmann et al. 1981). Depurated oysters were subsequently fed to volunteers who became ill, thus demonstrating that commercial depuration was not effective in eliminating NoV in contaminated oysters (Grohmann et al. 1981). In this case, volunteer studies provided definitive answers about the infectiousness of the shellfish. Volunteer studies can provide a firm basis for developing food and water processing strategies and for making regulatory decisions. Until such time that researchers develop a cell culture propagation system for $\mathrm{NoV}$, or other means to discriminate infectious from inactive NoV, human challenge studies are our best hope for determining true virus inactivation parameters.

This recommendation to limit surrogate studies will be highly controversial, since funding for surrogate research has been plentiful and many researchers (including those in my laboratory) are accustomed to conducting $\mathrm{NoV}$ research with virus surrogates. However, a shift in research directions is essential if we are to identify realistic and practical processing strategies to improve food safety. Former and present research conducted with NoV surrogates will likely contribute little to improving the world's food supply, while the costs of such studies could be pooled and redirected to more definitive clinical trials on NoV inactivation. Future surrogate studies should be considered only when the research is well justified with a clear delineation of why a study with surrogates is appropriate and what definitive information is anticipated. Surrogate studies should be linked, to the extent possible, with NoV volunteer studies to determine if the inactivation rates of surrogates and NoVs correlate after various processing interventions. Similar inactivation profiles would validate the surrogate for a particular use under defined conditions.

Clinical trials will again be necessary to validate some of the new and upcoming assays that are designed to differentiate infectious from inactivated viruses, such as pretreatment of viruses with proteinase $\mathrm{K}$ and ribonuclease before RT-PCR (Nuanualsuwan and Cliver 2002), use of ethidium and propidium monoazide in conjunction with RT-PCR assays (Kim et al. 2011; Parshionikar et al. 2010), and various receptor and binding assays, like one developed by Li et al. (2011) using MNV. Virus surrogates may play a role in the development of assays for NoV infectivity; however, confirmation that the surrogates are truly representative of NoV must be accomplished by volunteer studies. For instance, receptor binding assays which show that MNV only binds when it is infectious, should be linked with volunteer studies designed to evaluate the assay using NoV of demonstrated infectivity, as determined by clinical trials. Many in vitro surrogate studies suggest that NoV can be inactivated by one treatment or another, but fail to carry the work forward to validate the results using similar treatments of NoV in volunteer studies.

Over the years, a number of NoV volunteer studies have been performed. My laboratory just completed a 5-year collaborative study that involved clinical trials at Emory University in Atlanta (Leon et al. 2011). Since 1994, there were seven separate trials involving 190 volunteers at Emory University and the University of North Carolina at Chapel Hill (Lindesmith et al. 2003, 2005, 2010) and there were no adverse reactions among any of the volunteers (personal communication, Christine Moe, Emory University). Other clinical trials involving NoVs have been performed at Baylor College of Medicine (Graham et al. 1994; Hutson et al. 2002, 2005) and elsewhere (Wyatt et al. 1974; Dolin et al. 1982). NoV illness is usually a temporary imposition where adverse effects outside of the usual nausea, diarrhea, and vomiting are seldom encountered; therefore, there is reasonable expectation that trials may be conducted with minimal risk of complications. Oversight of clinical trials must be provided by institutional review boards for human subjects or similar entities whose mission is to evaluate potential patient risks, to ensure they are minimized to the extent possible, and to weigh the risks versus benefits of the proposed research. Costs for studies vary greatly, but an average volunteer may expect compensation of approximately $\$ 1000$ (US) for their participation and incarceration in the hospital for 3 or 4 days. Hospital costs, labor, and overhead for researchers add to the overall expense, thus the cost of a volunteer study may approach \$500,000 (US) in today's market, depending on the number of volunteers required to provide statistically significant results. If monies that were normally used for surrogate studies were pooled, then multiple volunteer studies could likely be funded each year.

One obstacle to clinical trials is the perception that such trials are risky. The threat of lawsuits, in the event of unforeseen circumstances, prevents some governments, universities, and hospitals from conducting or considering the funding of such studies. In reality, there is far more risk in allowing millions of unsuspecting consumers to contract NoV each year, when practical interventions are only a few volunteer studies away. The price to pay for inactivity is great, with lost wages, medical costs, and regulatory and epidemiological expenses involved in tracking and managing outbreaks. Costs of supporting clinical trials would be a small price to pay for the considerable savings that would be brought about by even a modest reduction in NoV outbreaks. A change in attitudes and a shift in research priorities are essential if we are to win the battle against NoV illness.

Acknowledgments The author thanks Michael Watson for technical assistance and David Kingsley and Clytrice Watson for review of the manuscript. 
Open Access This article is distributed under the terms of the Creative Commons Attribution Noncommercial License which permits any noncommercial use, distribution, and reproduction in any medium, provided the original author(s) and source are credited.

\section{References}

Bae, J., \& Schwab, K. J. (2008). Evaluation of murine norovirus, feline calicivirus, poliovirus, and MS2 as surrogates for human norovirus in a model of viral persistence in surface water and groundwater. Applied and Environmental Microbiology, 74, $477-484$

Baert, L., Uyttendaele, M., Van Coillie, E., \& Debevere, J. (2008a). The reduction of murine norovirus $1, B$. fragilis HSP40 infecting phage $\mathrm{B} 40-8$ and $E$. coli after mild thermal pasteurization process of raspberry puree. Food Microbiology, 25, 871-874.

Baert, L., Uyttendaele, M., Vermeersch, M., Van Coillie, E., \& Debevere, J. (2008b). Survival and transfer of murine norovirus 1 , a surrogate for human noroviruses, during the production process of deep-frozen onions and spinach. Journal of Food Protection, 71, 1590-1597.

Belliot, G., Lavaux, A., Souihel, D., Agnello, D., \& Pothier, P. (2008). Use of murine norovirus as a surrogate to evaluate resistance of human norovirus to disinfectants. Applied and Environmental Microbiology, 74, 3315-3318.

Buckow, R., Isbarn, S., Knorr, D., Heinz, V., \& Lehmacher, A. (2008). Predictive model for inactivation of feline calicivirus, a norovirus surrogate, by heat and high hydrostatic pressure. Applied and Environmental Microbiology, 74, 1030-1038.

Butot, S., Putallaz, T., Amoroso, R., \& Sánchez, G. (2009). Inactivation of enteric viruses in minimally processed berries and herbs. Applied and Environmental Microbiology, 75, 4155-4161.

Butot, S., Putallaz, T., \& Sánchez, G. (2008). Effects of sanitation, freezing and frozen storage on enteric viruses in berries and herbs. International Journal of Food Microbiology, 126, 30-35.

Cannon, J. L., Papafragkou, E., Park, G. W., Osborne, J., Jaykus, L. A., \& Vinjé, J. (2006). Surrogates for the study of norovirus stability and inactivation in the environment: A comparison of murine norovirus and feline calicivirus. Journal of Food Protection, 69, 2761-2765.

Chen, H., Hoover, D. G., \& Kingsley, D. H. (2005). Temperature and treatment time influence high hydrostatic pressure inactivation of feline calicivirus, a norovirus surrogate. Journal of Food Protection, 68, 2389-2394.

D'Souza, D. H., \& Su, X. (2010). Efficacy of chemical treatments against murine norovirus, feline calicivirus, and MS2 bacteriophage. Foodborne Pathogens and Disease, 7, 319-326.

Dawson, D. J., Paish, A., Staffell, L. M., Seymour, I. J., \& Appleton, H. (2005). Survival of viruses on fresh produce, using MS2 as a surrogate for norovirus. Journal of Applied Microbiology, 98, 203-209.

de Roda Husman, A. M., Bijkerk, P., Lodder, W., van den Berg, H., Pribil, W., Cabaj, A., et al. (2004). Calicivirus inactivation by nonionizing (253.7-nanometer-wavelength [UV]) and ionizing (gamma) radiation. Applied and Environmental Microbiology, 70, 5089-5093.

Di Martino, B., Ceci, C., Di Profio, \& Marsilio, F. (2010). In vitro inactivation of feline calicivirus (FCV) by chemical disinfectants: Resistance variation among field strains. Archives of Virology, 155, 2047-2051.

Dolin, R., Reichman, R. C., Roessner, K. D., Tralka, T. S., Schooley, R. T., Gary, W., et al. (1982). Detection by immune electron microscopy of the Snow Mountain agent of acute viral gastroenteritis. Journal of Infectious Diseases, 146, 184-189.

Doultree, J. C., Druce, J. D., Birch, C. J., Bowden, D. S., \& Marshall, J. A. (1999). Inactivation of feline calicivirus, a Norwalk virus surrogate. Journal of Hospital Infection, 41, 51-57.

Farkas, T., Cross, R. W., Hargitt, E., I. I. I., Lerche, N. M., Morrow, A. L., \& Sestak, K. (2010). Genetic diversity and histo-blood group antigen interactions of rhesus enteric caliciviruses. Journal of Virology, 84, 8617-8625.

Feng, K., Divers, E., Ma, Y., \& Li, J. (2011). Inactivation of a human norovirus surrogate, human norovirus virus-like particles, and vesicular stomatitis virus by gamma irradiation. Applied and Environmental Microbiology, 77, 3507-3517.

Fino, V. R., \& Kniel, K. E. (2008). UV light inactivation of hepatitis A virus, Aichi virus, and feline calicivirus on strawberries, green onions, and lettuce. Journal of Food Protection, 71, 908-913.

Gehrke, C., Steinmann, J., \& Goroncy-Beemes, P. (2004). Inactivation of feline calicivirus, a surrogate of norovirus (formerly Norwalk-like viruses), by different types of alcohol in vitro and in vivo. Journal of Hospital Infection, 56, 49-55.

Gibson, K. E., \& Schwab, K. J. (2011). Thermal inactivation of human norovirus surrogates. Food and Environmental Virology, 3, 74-77.

Graham, D. Y., Jiang, X., Tanaka, T., Opekum, A. R., Madore, H. P., \& Estes, M. K. (1994). Norwalk virus infection of volunteers: New insights based on improved assays. Journal of Infectious Diseases, 170, 34-43.

Grohmann, G. S., Murphy, A. M., Christopher, P. J., Auty, G., \& Greenberg, H. B. (1981). Norwalk virus gastroenteritis in volunteers consuming depurated oysters. Australian Journal of Experimental Biology and Medical Science, 59, 219-228.

Grove, S. F., Lee, A., Stewart, C. M., \& Ross, T. (2009). Development of a high pressure processing inactivation model for hepatitis A virus. Journal of Food Protection, 72, 1434-1442.

Hewitt, J., \& Greening, G. E. (2004). Survival and persistence of norovirus, hepatitis A virus, and feline calicivirus in marinated mussels. Journal of Food Protection, 67, 1743-1750.

Hewitt, J., Rivera-Aban, M., \& Greening, G. E. (2009). Evaluation of murine norovirus as a surrogate for human norovirus and hepatitis A virus in heat inactivation studies. Journal of Applied Microbiology, 107, 65-71.

Hudson, J. B., Sharma, M., \& Petric, M. (2007). Inactivation of norovirus by ozone gas in conditions relevant to healthcare. Journal of Hospital Infection, 66, 40-45.

Hutson, A. M., Airaud, F., LePendu, J., Estes, M. K., \& Atmar, R. L. (2005). Norwalk virus infection associates with secretor status genotypes from sera. Journal of Medical Virology, 77, 116-120.

Hutson, A. M., Atmar, R. L., Graham, D. Y., \& Estes, M. K. (2002). Norwalk virus infection and disease is associated with $\mathrm{ABO}$ histo-blood group type. Journal of Infectious Diseases, 185, 1335-1337.

Jean, J., Morales-Rayas, R., Anoman, M. N., \& Lamhoujeb, S. (2011). Inactivation of hepatitis A virus and norovirus surrogate in suspension and on food-contact surfaces using pulsed UV light (pulsed light inactivation of food viruses). Food Microbiology, $28,568-572$.

Jimemez, L., \& Chiang, M. (2006). Virucidal activity of quaternary ammonium compound disinfectant against feline calicivirus: A surrogate for norovirus. American Journal of Infection Control, $34,269-273$.

Kampf, G., Grotheer, D., \& Steinmann, J. (2005). Efficacy of three ethanol-based hand rubs against feline calicivirus, a surrogate virus for norovirus. Journal of Hospital Infection, 60, 144-149.

Kim, K., Katayama, H., Kitajima, M., Tohya, Y., \& Ohgaki, S. (2011). Development of a real- time RT-PCR assay combined 
with ethidium monoazide treatment for RNA viruses and its application to detect viral RNA after heat exposure. Water Science and Technology, 63, 502-507.

Kingsley, D. H., Holliman, D. R., Calci, K. R., Chen, H., \& Flick, G. J. (2007). Inactivation of a norovirus by high-pressure processing. Applied and Environmental Microbiology, 73, 581-585.

Kingsley, D. H., Hoover, D. G., Papafragkou, E., \& Richards, G. P. (2002). Inactivation of hepatitis A virus and a calicivirus by high hydrostatic pressure. Journal of Food Protection, 65, 1605-1609.

Koopmans, M., \& Duzier, E. (2004). Foodborne viruses: An emerging problem. International Journal of Food Microbiology, 90, 23-41.

Kroneman, A., Verhoef, L., Harris, J., Vennema, H., Duzier, E., van Duynhoven, Y., et al. (2008). Analysis of integrated virological and epidemiological reports of norovirus outbreaks collected within the foodborne viruses in Europe Network from 1 July 2001 to 30 June 2006. Journal of Clinical Microbiology, 46, 2959-2965.

Lages, S. L., Ramakrishnan, M. A., \& Goyal, S. M. (2008). In vivo efficacy of hand sanitizers against feline calicivirus: A surrogate for norovirus. Journal of Hospital Infection, 68, 159-163.

Le Guyader, F., Loisy, F., Atmar, R. L., Hutson, A. M., Estes, M. K., Ruvoën-Clouet, N., et al. (2006). Norwalk virus-specific binding to oyster digestive tissues. Emerging Infectious Diseases, 12, 931-936.

Lee, K. M., \& Gillespie, J. H. (1973). Thermal and pH stability of feline calicivirus. Infection and Immunity, 7, 678-679.

Lee, J., Zoh, K., \& Ko, G. (2008). Inactivation and UV disinfection of murine norovirus with $\mathrm{TiO}_{2}$ under various environmental conditions. Applied and Environmental Microbiology, 74, 2111-2117.

Leon, J. S., Kingsley, D. H., Monter, J. S., Richards, G. P., Lyon, G. M., Abdulhafid, G. M., et al. (2011). Randomized, doubleblinded clinical trial for human norovirus inactivation in oysters by high hydrostatic pressure processing. Applied and Environmental Microbiology, 77, 5476-5482.

Li, D., Baert, L., Van Coillie, E., \& Uyttendaele, M. (2011). Critical studies on binding-based RT-PCR detection of infectious noroviruses. Journal of Virological Methods, 177, 153-159.

Lim, M. Y., Kim, J. M., Lee, J. E., \& Ko, G. (2010). Characterization of ozone disinfection of norovirus. Applied and Environmental Microbiology, 76, 1120-1124.

Lindesmith, L. C., Donaldson, E., Leon, J., Moe, C. L., Frelinger, J. A., Johnston, R. E., et al. (2010). Heterotypic humoral and cellular immune responses following Norwalk virus infection. Journal of Virology, 84, 1800-1815.

Lindesmith, L., Moe, C., LePendu, J., Frelinger, J. A., Treanor, J., \& Baric, R. S. (2005). Cellular and humoral immunity following Snow Mountain virus challenge. Journal of Virology, 79, 2900-2909.

Lindesmith, L., Moe, C., Marionneau, S., Ruoven, N., Jiang, X., Lindblad, L., et al. (2003). Human susceptibility and resistance to Norwalk virus infection. Nature Medicine, 9, 548-553.

Lou, F., Neetoo, H., Chen, H., \& Li, J. (2011). Inactivation of a human norovirus surrogate by high-pressure processing: Effectiveness, mechanism, and potential application in the fresh produce industry. Applied and Environmental Microbiology, 77, $1862-1871$.

Maalouf, H., Schaeffer, J., Parnaudeau, S., Le Pendu, J., Atmar, R. L., Crawford, S. E., et al. (2011). Strain-dependent norovirus bioaccumulation in oysters. Applied and Environmental Microbiology, 77, 3189-3196.

Magulski, T., Paulmann, D., Bischoff, B., Becker, B., Steinmann, E., Steinmann, J., et al. (2009). Inactivation of murine norovirus by chemical biocides on stainless steel. BMC Infectious Diseases, 9, 107.

Malik, Y. S., \& Goyal, S. M. (2006). Virucidal efficacy of sodium bicarbonate on a food contact surface against feline calicivirus, a norovirus surrogate. International Journal of Food Microbiology, 109, 160-163.

Malik, Y. S., Maherchandani, S., \& Goyal, S. M. (2006). Comparative efficacy of ethanol and isopropanol against feline calicivirus, a norovirus surrogate. American Journal of Infection Control, 34, $31-35$.

Mead, P. S., Slutsker, L., Dietz, V., McCaig, L. F., Bresee, J. S., Shapiro, C., et al. (1999). Food-related illness and death in the United States. Emerging Infectious Diseases, 5, 607-625.

Mori, K., Hayashi, Y., Akiba, T., Noguchi, Y., Yoshida, Y., Kai, A., et al. (2007). Effects of hand hygiene on feline calicivirus inactivation and removal as norovirus surrogate treated with antiseptic hand rubbing, wet wipes, and functional water. Kansenshogaku Zasshi, 81, 249-255.

Morino, H., Fukuda, T., Miura, T., Lee, C., Shibata, T., \& Sanekata, T. (2009). Inactivation of feline calicivirus, a norovirus surrogate, by chlorine dioxide gas. Biocontrol Science, 14, 147-153.

Nuanualsuwan, S., \& Cliver, D. O. (2002). Pretreatment to avoid positive RT-PCR results with inactivated viruses. Journal of Virological Methods, 104, 217-225.

Nuanualsuwan, S., Mariam, T., Himathongkham, S., \& Cliver, D. O. (2002). Ultraviolet inactivation of feline calicivirus, human enteric viruses and coliphages. Photochemistry and Photobiology, 76, 406-410.

Park, G. W., Barclay, L., Macinga, D., Charbonneau, D., Pettigrew, C. A., \& Vinjé, J. (2010). Comparative efficacy of seven hand sanitizers against murine norovirus, feline calicivirus, and GII.4 norovirus. Journal of Food Protection, 73, 2232-2238.

Park, G. W., Linden, K. G., \& Sobsey, M. D. (2011). Inactivation of murine norovirus, feline calicivirus and echo 12 as surrogates for human norovirus (NoV) and coliphage $\left(\mathrm{F}^{+}\right)$MS2 by ultraviolet light $(254 \mathrm{~nm})$ and the effect of cell association on UV inactivation. Letters in Applied Microbiology, 52, 162-167.

Parshionikar, S., Laeske, I., \& Fout, G. S. (2010). Use of propidium monoazide in reverse transcriptase PCR to distinguish between infectious and noninfectious enteric viruses in water samples. Applied and Environmental Microbiology, 76, 4318-4326.

Phillips, G., Tam, C. C., Conti, S., Rodrigues, L. C., Brown, D., Iturriza-Gomara, M., et al. (2010). Community incidence of norovirus-associated infectious intestinal disease in England: Improved estimates using viral load for norovirus diagnostics. American Journal of Epidemiology, 171, 1014-1022.

Poschetto, L. F., Ike, A., Papp, T., Mohn, U., Böhm, R., \& Marschang, R. E. (2007). Comparison of the sensitivities of noroviruses and feline calicivirus to chemical disinfection under field-like conditions. Applied and Environmental Microbiology, 73, 5494-5500.

Predmore, A., \& Li, J. (2011). Enhanced removal of a human norovirus surrogate from fresh vegetables and fruits by a combination of surfactants and sanitizers. Applied and Environmental Microbiology, 77, 4829-4838.

Richards, G. P. (1999). Limitations of molecular biological techniques for assessing the virological safety of foods. Journal of Food Protection, 62, 691-697.

Richards, G. P. (2001). Enteric virus contamination of foods through industrial practices: A primer on intervention strategies. Journal of Industrial Microbiology \& Biotechnology, 27, 117-125.

Richards, G. P., McLeod, C., \& Le Guyader, F. S. (2010). Processing strategies to inactivate viruses in shellfish. Food and Environmental Virology, 2, 183-193.

Sanglay, G. C., Li, J., Uribe, R. M., \& Lee, K. (2011). Electron-beam inactivation of a norovirus surrogate in fresh produce and model systems. Journal of Food Protection, 74, 1155-1160.

Sattar, S. A., Ali, M., \& Tetro, J. A. (2011). In vivo comparison of two norovirus surrogates for testing ethanol-based handrubs: The mouse chasing the cat! PLoS One, 6, e17340. 
Scallan, E., Hoekstra, R. M., Angulo, F. J., \& Tauxe, R. V. (2011). Foodborne illness acquired in the United States-major pathogens. Emerging Infectious Diseases, 17, 7-15.

Shimasaki, N., Kiyohara, T., Totsuka, A., Nojima, K., Okada, Y., Yamaguchi, K., et al. (2009). Inactivation of hepatitis A virus by heat and high hydrostatic pressure: Variation among laboratory strains. Vox Sanguinis, 96, 14-19.

Shin, G. A., \& Sobsey, M. D. (2003). Reduction of Norwalk virus, poliovirus 1 , and bacteriophage MS2 by ozone disinfection of water. Applied and Environmental Microbiology, 69, 3975-3978.

Siebenga, J. J., Vennema, H., Zheng, D. P., Vinjé, J., Lee, B. E., Pang, X. L., et al. (2009). Norovirus illness is a global problem: Emergence and spread of norovirus GII.4 variants, 2001-2007. Journal of Infectious Diseases, 200, 802-812.

Slomka, M. J., \& Appleton, H. (1998). Feline calicivirus as a model system for heat inactivation studies of small round structured viruses in shellfish. Epidemiology and Infection, 121, 401-407.

Sow, H., Desbiens, M., Morales-Rayas, R., Ngazoa, S. E., \& Jean, J. (2011). Heat inactivation of hepatitis A virus and a norovirus surrogate in soft-shell clams (Mya arenaria). Foodborne Pathogens and Disease, 8, 387-393.

Steinmann, J. (2004). Surrogate viruses for testing virucidal efficacy of chemical disinfectants. Journal of Hospital Infection, 56(Suppl. 2), S49-S54.

Stuart, A. D., \& Brown, T. D. (2007). Alpha2, 6-linked sialic acid acts as a receptor for feline calicivirus. Journal of General Virology, 88, 177-186.

Tan, M., \& Jiang, X. (2010). Norovirus gastroenteritis, carbohydrate receptors, and animal models. PLoS Pathogens, 6, e1000983.

Tang, Q., Li, D., Xu, J., Wang, J., Zhao, Y., Li, Z., et al. (2010). Mechanism of inactivation of murine norovirus-1 by high pressure processing. International Journal of Food Microbiology, 137, 186-189.

Tanner, B. D. (2009). Reduction in infection risk through treatment of microbially contaminated surfaces with a novel, portable, saturated steam vapor disinfection system. American Journal of Infection Control, 37, 20-27.
Taube, S., Perry, J. W., Yetming, K., Patel, S. P., Auble, H., Shu, L., et al. (2009). Ganglioside-linked terminal sialic acid moieties on murine macrophages function as attachment receptors for murine noroviruses (MNV). Journal of Virology, 83, 4092-4101.

Tian, P., Bates, A. H., Jensen, H. M., \& Mandrell, R. E. (2006). Norovirus binds to blood group A-like antigens in oyster gastrointestinal cells. Letters in Applied Microbiology, 43, 645-651.

Tian, P., Engelbrektson, A. L., Jiang, X., Zhong, W., \& Mandrell, R. E. (2007). Norovirus recognizes histo-blood group antigens on gastrointestinal cells of clams, mussels, and oysters: A possible mechanism of bioaccumulation. Journal of Food Protection, 70, 2140-2147.

Ueki, Y., Shoji, M., Suto, A., Tanabe, T., Okimura, Y., Kikuchi, Y., et al. (2007). Persistence of calicivirus in artificially contaminated oysters during depuration. Applied and Environmental Microbiology, 73, 5698-5701.

Urakami, H., Ikarashi, K., Okamoto, K., Abe, Y., Ikarashi, T., Kono, T., et al. (2007). Chlorine sensitivity of feline calicivirus, a norovirus surrogate. Applied and Environmental Microbiology, 73, 5679-5682.

Whitehead, K., \& McCue, K. A. (2010). Virucidal efficacy of disinfectant activities against feline calicivirus, a surrogate for norovirus, in a short contact time. American Journal of Infection Control, 38, 26-30.

Wilkinson, N., Kurdziel, A. S., Langton, S., Needs, E., \& Cook, N. (2001). Resistance of poliovirus to inactivation by high hydrostatic pressure. Innovative Food Science and Emerging Technologies, 2, 95-98.

Wobus, C. E., Thackray, L. B., \& Virgin, H. W., I. V. (2006). Murine norovirus: A model system to study norovirus biology and pathogenesis. Journal of Virology, 80, 5104-5112.

Wyatt, R. G., Dolin, R., Blacklow, N. R., DuPont, H. L., Buscho, R. F., Thornhill, T. S., et al. (1974). Comparison of three agents of acute infectious nonbacterial gastroenteritis by cross-challenge of volunteers. Journal of Infectious Diseases, 129, 709-714. 